\title{
Systematic Research on the Application of Steel Slag Resources under the Background of Big Data
}

\author{
Le Kang $\mathbb{D}^{1}{ }^{1}$ Hui Ling Du, ${ }^{1}$ Hao Zhang, ${ }^{2}$ and Wan Li Ma ${ }^{1}$ \\ ${ }^{1}$ College of Materials Science and Engineering, Xi'an University of Science and Technology, Xi'an 710054, China \\ ${ }^{2}$ School of Civil Engineering and Architecture, Anhui University of Technology, Ma'anshan 243032, China
}

Correspondence should be addressed to Le Kang; kangle20140805@126.com

Received 18 May 2018; Accepted 12 August 2018; Published 8 October 2018

Academic Editor: Zhihan Lv

Copyright (c) 2018 Le Kang et al. This is an open access article distributed under the Creative Commons Attribution License, which permits unrestricted use, distribution, and reproduction in any medium, provided the original work is properly cited.

\begin{abstract}
The large-scale and resourceful utilization of solid waste is one of the important ways of sustainable development. The big data brings hope for further development in all walks of life, because huge amounts of data insist on the principle of "turning waste into treasure". The steel big data has been taken as the research object in this paper. Firstly, a big data collection and storage system has been set up based on the Hadoop platform. Secondly, the steel slag prediction model based on the convolution neural network $(\mathrm{CNN})$ is established. The material data of steelmaking, the operation data of steelmaking process, and the data of steel slag composition are put into the model from the Hadoop platform, and the prediction of the slag composition is further realized. Then, the alternatives for resource recovery are obtained according to the predicted composition of the steel slag. And considering the three aspects of economic feasibility, resource suitability, and environmental acceptance, the comprehensive evaluation system based on AHP is established to realize the recommendation of the optimal resource approach. Finally, taking a steel plant in Hebei as an example, the alternatives according to the prediction of the composition of steel slag are blast furnace iron-making, recycling waste steel, and cement admixture. The comprehensive evaluation values of the three resources are $0.48,0.57$, and 0.76 , respectively, and the optimized resource of the steel slag produced by the steel plant is used as the cement admixture.
\end{abstract}

\section{Introduction}

In steel companies, steel slag accounts for $8 \%$ to $15 \%$ of crude steel production as a by-product, and more than 80 million tons of steel slag is discharged in China every year. With the rapid development of the domestic metallurgical industry, the production of steel slag has increased year by year. At the same time, due to the inability to timely dispose steel slag, it not only occupies a large amount of land but also pollutes the environment and even affects the health of the human body $[1,2]$. Currently, most of the studies of steel slag are limited to use as the raw material of calcining cement clinker, road-building material, concrete admixture, soil amendment, and a kind of adsorbent in wastewater treatment. By making researches on the utilization of steel slag treatment technology that is used to improve the efficiency of resource utilization, it aims to further realize the construction of green industry chain and the development of the circular economy. The foreign steel companies increased the recycling efficiency of steel slag products within the company to more than $98 \%$, which basically reached zero emission targets. Because of its own activity, stability, and other reasons, the utilization efficiency of domestic steel slag is only about $22 \%$, resulting in a serious waste of resources. Among them, 50\% of steel slag has been used for the road project directly, with the remaining part for sintering and iron-making recycling in the plant. The resource application technology of steel slag is usually based on the research and development of steel slag composition and structure. Therefore, the raw materials and procedures of the steelmaking are studied, and the resource method of steel slag is established by constructing the prediction model of steel slag composition, so as to achieve the purpose of the application of steel slag. 


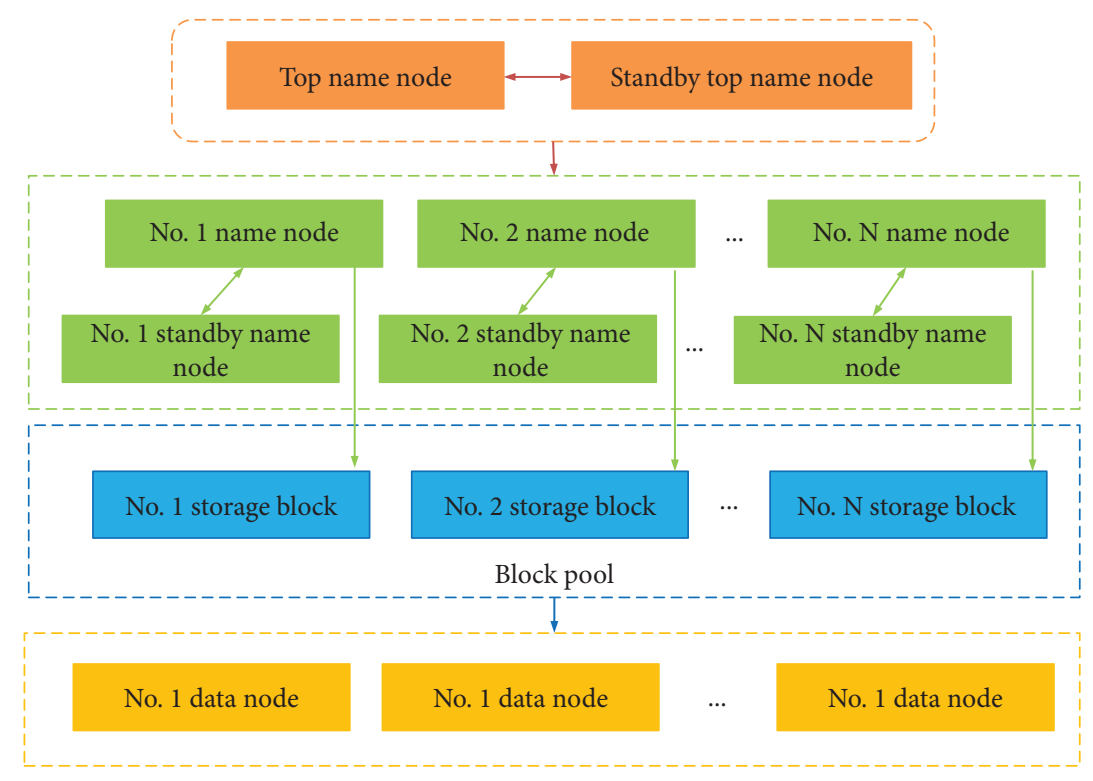

FIgURE 1: The structure diagram of HDFS system for distributed nodes.

In the process of steelmaking, both the upstream and downstream production lines are longer. A large number of data are obtained by installing various kinds of sensors and testing equipment, and the data are fed to the staff of the console to make corresponding instructions and operations. In this paper, a large data platform is built to collect and store real-time dynamic steelmaking production data, and the Hadoop distributed file system (HDFS) is used to realize the virtual resource storage of large data in the steelmaking process. The CNN convolution neural network algorithm [3] is used to predict the composition of steel slag; the prediction is made to provide a basic basis for the application of the steel slag resource application recommendation system. Based on this, a resource utilization system of steel slag based on the background of big data is established, which will eventually provide new ideas for steel slag treatment and application in steel companies.

\section{Big Data Acquisition and Storage System for Steelmaking Based on Hadoop Platform}

2.1. Hadoop Software Framework. Hadoop is a combination of MapReduce parallel computing framework and NDFS distributed file system used to support the Nutch algorithm program, and then the independent and complete software is developed [4]. That is to say, it is an open source + distributed storage + distributed computing platform. The principle is to extend a single server into a cluster class machine. Each node provides local computing and storage without relying on hardware to achieve high availability. As a core component, MapReduce is used to implement task decomposition and scheduling, and HDFS is used to store massive amounts of data. With real-time storage of flow data obtained in the steelmaking process, and further effective calculation that was made, it aims to make full use of the application value of Hadoop software.
2.2. Research on Distributed Optimization of HDFS Based on Big Data. In the traditional Hadoop framework, the NameNode node is single and there is a bottleneck in single point performance. In order to deal with issues of efficient storage and real-time processing of big data, the HDFS optimization design for distributed NameNode nodes is proposed, and the HDFS cluster coordination nodes are constructed to achieve high availability of the NameNode node system [5], as shown in Figure 1.

As the control point of the NameNode node, the TopNameNode node is used to maintain the security of the system and the information data. By monitoring the nodes and handling the faults in time, the state information is forwarded and transmitted in real time to provide the metadata service for the HDFS. In the optimization design of HDFS, the process is the 5 key point of the design for the security mode of the NameNode when HDFS starts - the detection of TopNameNode failures-the recreation of the heartbeat package and the replica-the data interaction consistency - the signing of the lease. The advantages of the HDFS system based on distributed NameNode nodes are

(1) The fast handoff of NameNode/Secondary NameNode is realized, and the real-time invocation of HDFS is improved

(2) The service performance of the distributed NameNode is improved, and the clustering service client is adopted

(3) Hadoop clusters are extended to store large amounts of data

2.3. Storage Platform Framework Based on Big Data for Steel. According to the timeliness and large reserves of steel production data, the Hadoop distributed storage system is placed in the virtual pool of the resource management 


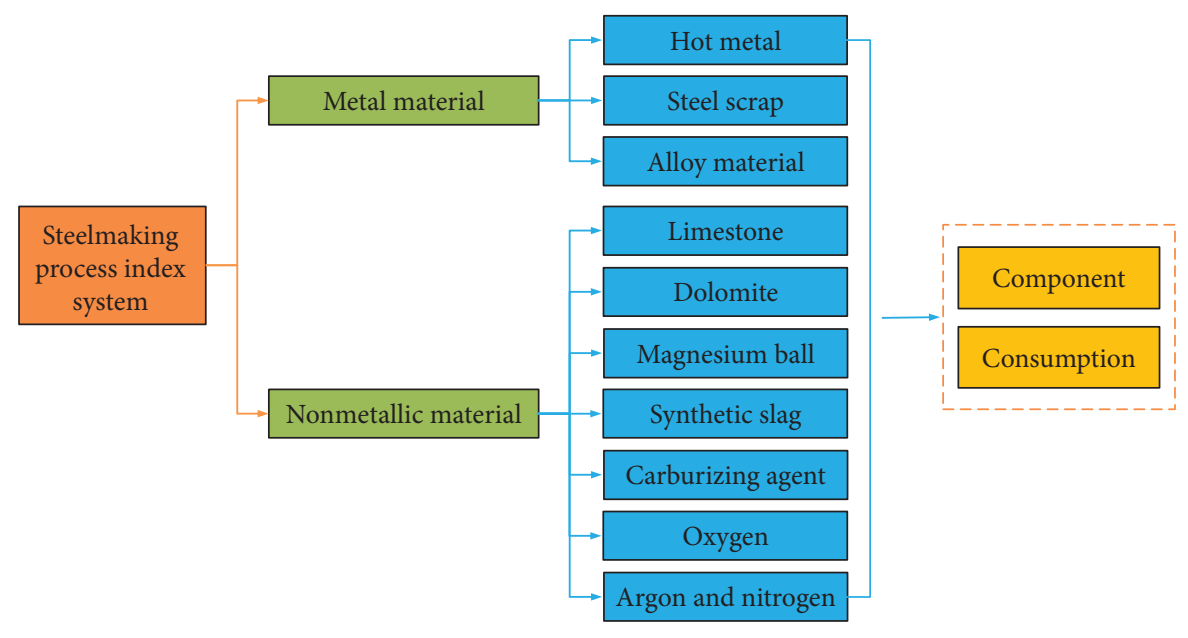

FIGURE 2: The index system based on steelmaking process.

platform, which has the characteristics of the dynamically deployed Hadoop slave nodes and the fast building of Hadoop distributed storage.

The new big data storage platform has good compatibility and long life cycle. The data of iron and steel process are stored on the platform in real time to realize data analysis and processing. Data storage includes quantitative data such as steelmaking raw materials, excipients, gas quantity, and operation process. The prediction of slag composition can be achieved during transmission with the prediction system.

\section{Construction of Index System Based on Steelmaking Production}

In the steel enterprise, the monitoring and acquisition system on the production line is constructed for a large amount of real-time flow data. The data is collected by sensors or detection instruments, and data is stored in the Hadoop data storage platform to realize data analysis and cooperative scheduling in the system. The data index of the steelmaking process takes the input, operation, and output of the converter or electric furnace as the theoretical process. However, the actual steelmaking process is more complicated, so it is studied in detail from the following aspects.

3.1. Steelmaking Raw Materials. As the input of the important energy sources, the quantity and proportion of steelmaking raw materials can finally affect the quality of the final product [6]. Basic steelmaking materials can be divided into metal materials and nonmetal materials according to the material composition. Among them, the metal raw materials are mainly molten iron and scrap steel, and the molten iron is a blast furnace product of ironworks; the composition and temperature of the molten metal are related to steel grades. As an important refrigerant, the specific gravity of scrap steel is maintained at about $35-40 \%$. At the same time, the type and composition of the alloy material can be used to determine deoxidization and balance the composition of the furnace according to the type of steelmaking.
Nonmetallic materials include slagging materials, oxidizing agents, carburizing agents, and coolants. The basic slagging materials are mainly limestone, dolomite, magnesium balls, and so on. In oxygenants, oxygen can rapidly increase the pool temperature and shorten the oxidation time as an important source of oxygen in the furnace. Iron ore and iron oxide are used as solid oxygenants to oxidize. The carburizing agent is used to control the carbon content of the molten steel. The coolant is mainly used to balance the heat in the furnace.

3.2. Operating System. During the process of steelmaking, a reasonable operation process can ensure the continuous stability of production, and it is also related to the quality control of steel products. The development of metallurgical industry has put forward five operating systems for the operation of the steel plant, which includes the loading system, the oxygen supply system, the slagging system, the temperature system, and the deoxidization alloying system [7]. Therefore, the quantifiable operating process is generally controlled for the amount of raw material charged, oxygen flow rate, argon and nitrogen flow rate, injection time, alloy amount, and so on. The steelmaking operation system controls the whole steelmaking process, so its quantifiable index coincides and crossover with the composition and content of the raw materials. In the process of constructing the steelmaking process index system, we follow the basic principles of comprehensiveness, scientificity, and typicality and determine the index system in combination with the above actual quantitative conditions, as shown in Figure 2.

The data corresponding to each index of the system are collected and stored on the Hadoop platform as the original sample set for the input of the prediction system. As a by-product of steelmaking, the composition of different steel slag determined by electron microscopy is the output sample of the prediction system. The depth learning framework of CNN convolution neural network is used to study the sample input and output of large data in historical steelmaking, and then the prediction of the composition of 
different steel slag is realized, which contributes to the utilization of steel slag resources in the later period.

\section{Prediction Model of Steel Slag Composition Based on Convolution Neural Network}

The convolution neural network, called CNN, is an important algorithm in the field of deep learning, which is improved by the BP neural network, including 5 parts of the input layer, convolution layer, activation function, pool layer, and full connection layer. The bias and connection weights among different neurons are constantly adjusted by using the combination of positive propagation of information and error reverse propagation [8]. It has the characteristics of local perception, weight sharing, and so on. In addition, its unique convolution layer, pool layer, and full connection layer make it capable with fast learning ability. And it can handle complex and large numbers of data quickly and efficiently. In this paper, it narrates material information, steelmaking process operation, and the data of final steel slag composition during the steelmaking process to explore the nonlinear relationship between the steel slag composition and the final steel slag composition, so as to guide the prediction of steel slag composition.

\subsection{The Principle of Convolution Neural Network}

4.1.1. Local Perception. Unlike the basic structure of the BP neural network, the convolution neural network changes the connection between the two adjacent layers by using the features of the local sensing area and uses the local connection method. The structure of the convolution neural network is illustrated in Figure 3.

As you can see in Figure 1, the nodes of the current layer are connected to the part of the previous layer, each of which is connected, thus it can reduce the number of weights and speed up the construction and training speed of the model quickly.

4.1.2. Weight Sharing. Weight sharing is the function of the filter on a layer of neuron nodes. And the small filter is equivalent to a local sensing area. And the weight sharing uses this filter on this layer of neuron nodes to reduce the number of parameters. In the CNN neural network, there are usually many filters in the neural network, as shown in Figure 4.

It can be seen that in Figure 4, the local connection and weight sharing are used between the two adjacent layers. The size of the local perception area is 3 . And the step length of each movement is 1 . The same color connection indicates the same weight value. It can greatly reduce the number of weight connection parameters of the neural network.

4.1.3. Convolution Layer. The convolution layer corresponds to the convolution process in the neural network. The input of the convolution layer may be the data of the input layer or the data after the pool layer. By using the convolution filter in all the characteristic spaces of the input data, and the data of the corresponding location in each perceptual area are multiplied by the weights in the convolution filter, and then

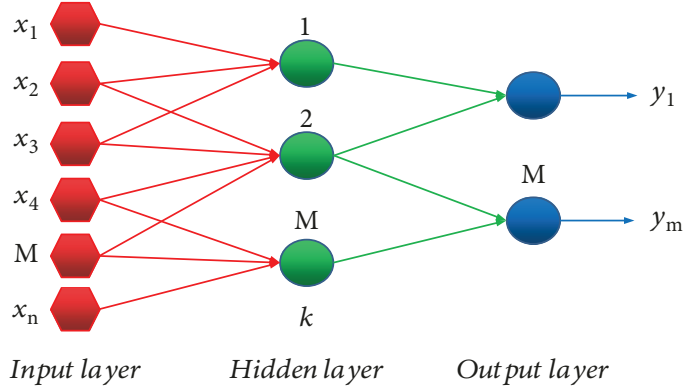

Figure 3: The structural diagram of local connection about CNN.

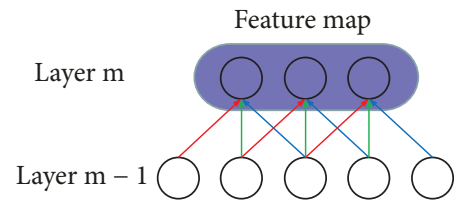

Figure 4: The schematic diagram of shared weight.

the addition is used as the input of the next layer of neurons. The formula of the convolution layer can be seen as

$$
y_{i}=f\left(\sum_{i=1}^{n} W_{i} x_{i}+\mathrm{b}\right) \text {, }
$$

where $y_{i}$ represents the result of convolution and $W_{i}$ represents the weight value of the convolution filter. The filter acts on all the nodes of the whole layer and performs convolution operations and outputs it to the next level. The convolution process is shown in Figure 5.

In the convolution process which is shown above, the node in the current layer reduces the weight parameter and the number of biases after the function of the convolution kernel, and the step length is 1 and the local perception size is 2 , and after the sum of the weighted sum, the activation function is used in the above result, and the fruit output to the next layer and one convolution process is over.

4.1.4. Pooling Layer. The pool layer is a sampling process for the results of the last convolution process. There are many processing methods. The results of the upper layer can be processed by the methods of maximum pool, mean pool, and summation. The maximum pool sampling is a nonlinear sampling method. It can reduce the dimension of the convolution results through the maximum pool sampling, thus reducing the number of parameters and reducing the complexity of the model. The sampling process of the pool layer is represented by Figure 6 .

In the process of sampling from the convolution results that are shown in the figure above, this sampling process can be used to select the maximum value or the mean of the given region. Here is the method of taking the average value of the sampling area, because there is no overlap in the pool process, and the final result is obtained after the convolution is removed. 


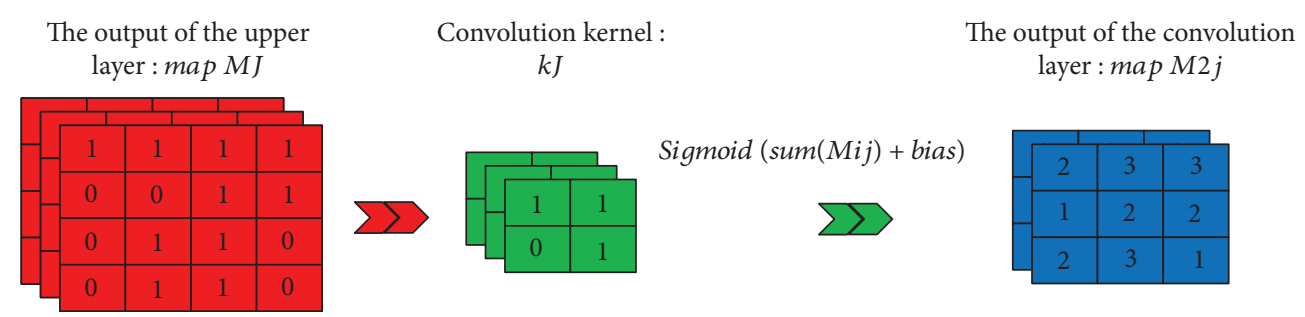

Figure 5: The schematic diagram of the convolution process.

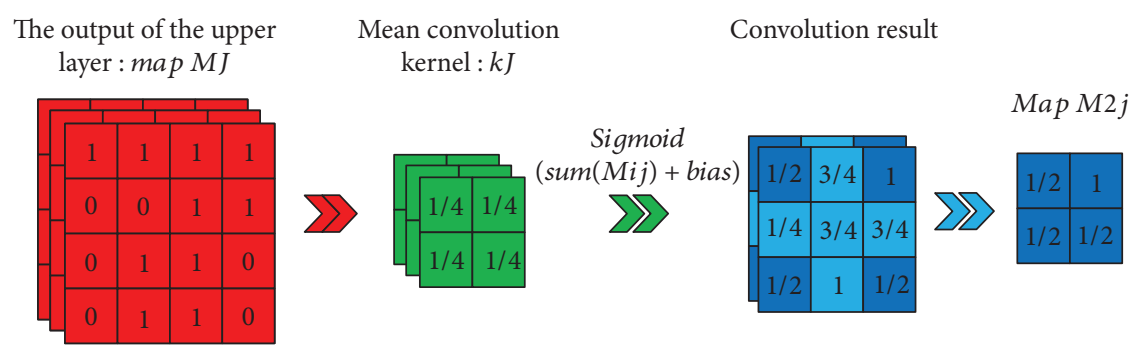

FIgURE 6: The schematic diagram of the pooling process.

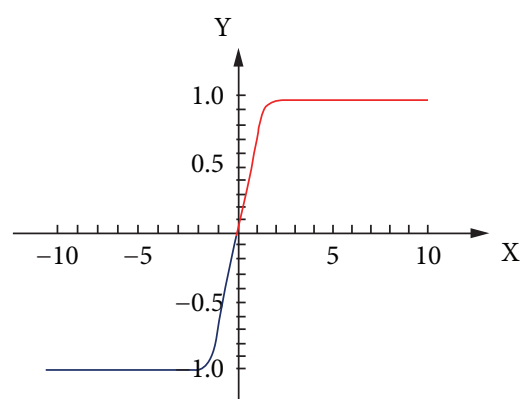

FIGURE 7: The image of the tanh function.

4.1.5. Fully Connected Layer. The convolution neural network usually adds a full connection layer after a number of convolution and pooling processes. The function of the full connection layer is to ensure that the features of the previous local connection will not loss. The results after convolution and pooling are combined to output the results. The calculation formula of the fully connected layer is as follows:

$$
y_{i}=f\left(\sum_{i=1}^{n} W_{i} x_{i}+\mathrm{b}_{i}\right) \text {, }
$$

where $f(x)$ represents an activation function, and there are 4 main types of activation functions: sigmoid function, relu function, prelu function, and tanh function. In this paper, the tanh function is used, and the formula is as follows:

$$
f(x)=\frac{e^{x}-e^{-x}}{e^{x}+e^{-x}} .
$$

The function image is shown in Figure 7.
4.2. Structural Design of Steel Slag Composition Prediction Model Based on Convolution Neural Network. In order to predict the composition of steel slag, the Hadoop platform should be established first to extract the related variables such as raw material information and steelmaking process parameters in the process of steelmaking. The original data is preprocessed and the processed data are used as the input layer of convolution neural network. When the data in the network passes through the input layer, it is transferred to the first layer of coiling layer. When the convolution operation occurs, the size of the convolution window, the size of the convolution core, and the sliding step need to be specified. The convolution filter is combined with the weighted data in the local sensing area to be sent to the activation function. After the processing of the activated function, the data is then exported to the pool layer. The sampling process is mainly done in the pooling layer, and dimension reduction is performed to reduce the complexity of the model. Then the data of the pooled layer is output to the convolution layer of the next layer to perform the same operation. Then, the result after the accumulation layer and the pool layer is exported to the full connection layer. The fully connected layer combines the features obtained before and fully connects with the output layer. After weighting and activating the function, the result is transmitted to the output layer, and the prediction results are obtained. According to the data collected in this paper, the design of the CNN network structure is shown in Figure 8.

As shown in Figure 4, the CNN network has 1 input layer, 6 volume layers, 6 pools, and a full connection layer and 1 output layer. The volume of convolution kernel in $1 \sim 6$ convolution layer of CNN network is $2^{*} 2$, and the number of convolution kernel is 20 . The 6 pools use the maximum sampling, and the kernel size is $2 * 2$. The activation function 


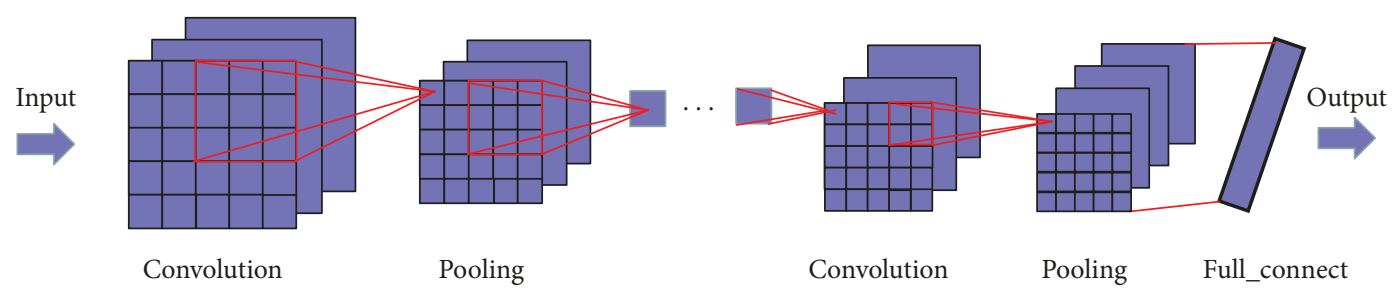

FIGURE 8: Neural network structure for predicting the composition of steel slag.

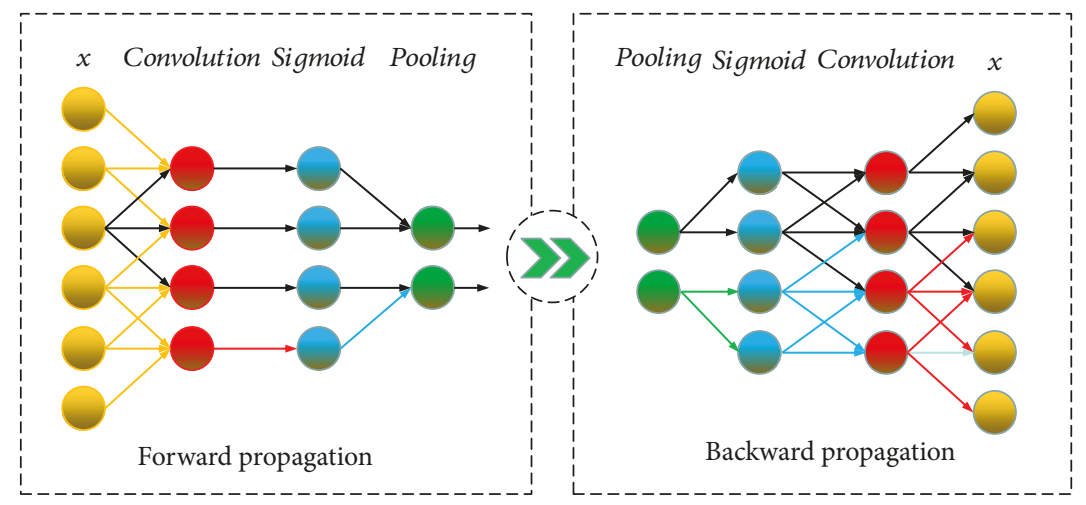

Figure 9: The schematic map of network training about CNN.

TABLE 1: Input and output indicators of CNN.

\begin{tabular}{|c|c|c|c|c|c|c|}
\hline Input vector $X_{i}$ & $x_{1}$ & $x_{2}$ & $x_{3}$ & $x_{4}$ & $\ldots$ & $x_{T}$ \\
\hline Input parameter & $\begin{array}{c}\text { Composition of } \\
\text { molten iron }\end{array}$ & Scrap ratio & $\begin{array}{l}\text { Lime composition } \\
\text { and dosage }\end{array}$ & $\begin{array}{c}\text { Fluorite quality } \\
\text { and dosage }\end{array}$ & $\cdots$ & $\begin{array}{l}\text { The number of adding } \\
\text { slagging constituent }\end{array}$ \\
\hline Output vector $Y_{j}$ & $y_{1}$ & $y_{2}$ & $y_{3}$ & $y_{4}$ & $\ldots$ & $y_{m}$ \\
\hline Output parameter & $\mathrm{CaO}$ & $\mathrm{Fe}_{2} \mathrm{O}_{3}$ & $\mathrm{SO}_{2}$ & $\mathrm{Al}_{2} \mathrm{O}_{3}$ & $\ldots$ & $\mathrm{P}_{2} \mathrm{O}_{5}$ \\
\hline
\end{tabular}

uses the relu function, and the total number of all connected layer neurons is 25 .

\subsection{Training of Prediction Model about Steel Slag} Composition Based on Convolution Neural Network. The parameter adjustment of the CNN network model is to calculate the gradient in each layer according to the gradient descent algorithm. In this process, the weights and biases are constantly updated, until the gradient changes arrive at the specified threshold or do not change, and the learning process [9] is stopped. The training algorithm includes the forward propagation of information and the backward propagation of errors. In the forward propagation phase of information, the data of the input layer is passed to the middle layer first. After connecting with the middle volume layer, the pool layer, and the full connection layer, the prediction value is finally obtained. Then the output value and the target value are compared. If the comparison value exceeds the threshold, it enters the reverse propagation stage of error. According to the error of the output layer, the error of the upper layer is obtained by the gradient descent, and then the weight value is adjusted to the first coiling layer, and the weight value and the bias value are constantly updated. The specific process is shown in Figure 9.

Raw material information and steelmaking process data are taken as input items, steel slag composition data are taken as output items, and steel slag composition prediction model is trained. Steel slag is a by-product of the steelmaking process, its composition change has a certain time series, and the change of steel slag composition is closely related to the historical data during the whole process of steelmaking. The input and output list of CNN neural network are shown in Table 1.

Establish the correspondences of multiple input and output as shown in Table 1, the index data of the extracted steelmaking materials and steelmaking process are taken as input vectors $X=\left(x_{1}, x_{2}, \ldots, x_{T}\right)$ and the composition of the steel slag are taken as output vectors $Y=\left(y_{1}, y_{2}, \ldots, y_{m}\right)$. With CNN network training data, $80 \%$ of the sample data 


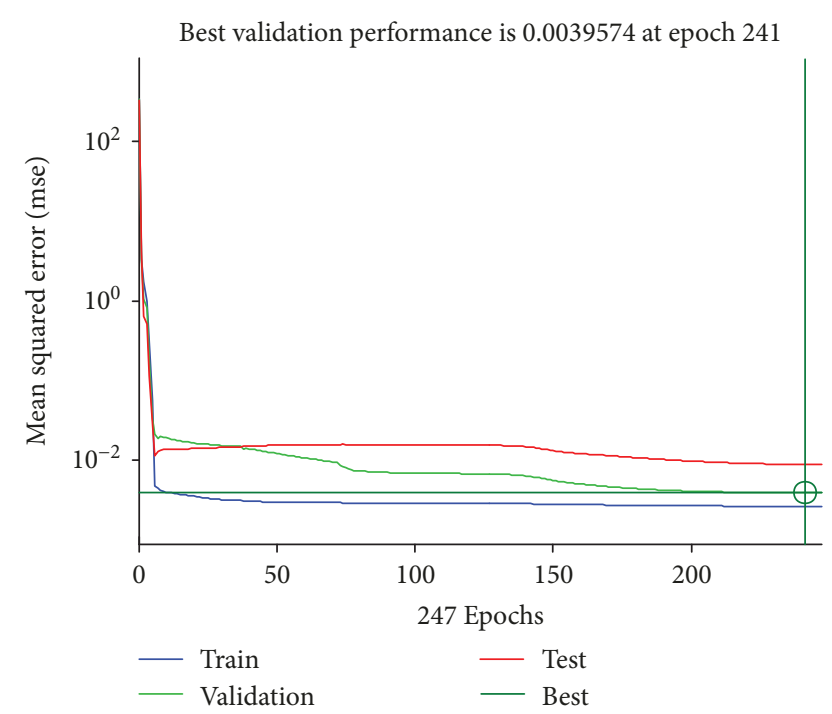

FIgURE 10: The training of CNN.

is randomly selected for training and $20 \%$ as the test set. This process is implemented with the aid of the programming of MATLAB software. The effect of iteration is shown in Figures 10 and 11.

According to the result of iteration, the result of model training is the best, and the error of the test set is also up to the test requirement. It is important to save the network and use it to predict the composition of steel slag in actual production.

\section{Establishment of Recommended System for Steel Slag Reclamation Based on AHP}

The resourceful application of steel slag should be considered from the three aspects: economy, environment, and resources. We should choose the right way to maximize the treatment and utilization of steel slag. Therefore reasonable recommendation system for resource utilization of steel slag is constructed based on the composition of steel slag to recommend the way of resource utilization.

5.1. The Way of Steel Slag Resources. The resource utilization way of steel slag is determined by the composition of steel slag, and the alkalinity of steel slag is an important factor that determines its treatment and application. The alkalinity is expressed in $\mathrm{A}$, refers to the ratio of $\mathrm{CaO}$ to $\mathrm{SiO}_{2}$ and $\mathrm{P}_{2} \mathrm{O}_{5}$, which can be expressed as

$$
R=\frac{w(\mathrm{CaO})}{w\left(\mathrm{SiO}_{2}\right)+w\left(\mathrm{P}_{2} \mathrm{O}_{5}\right)}
$$

According to the degree of alkalinity, steel slag is usually divided into low alkalinity slag, medium alkalinity slag, and high alkalinity slag, whose ranges are 1.30 1.50, 1.80 2.50, and more than 2.50. The slag used in resource utilization is mainly intermediate slag and high alkalinity slag. In the process of exploring the application way of steel slag resource, after referring to some references and making

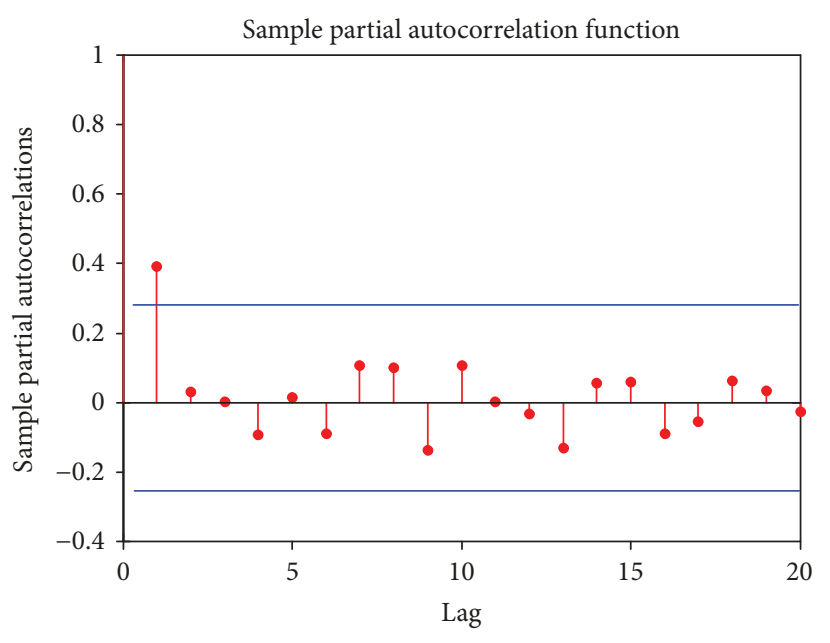

FIgURE 11: Error graph of the training of CNN.

actual enterprise investigation, the high rate treatment method is taken as the consideration to realize the resource application of steel slag [10].

The approaches to the application of steel slag to internal circulation are

Steel slag is used as sinter flux. Based on the main chemical components of steel slag includes $\mathrm{CaO}, \mathrm{FeO}$, $\mathrm{Al}_{2} \mathrm{O}_{3}, \mathrm{SiO}_{2}$, and $\mathrm{MgO}$. When the content of $\mathrm{CaO}$ exceeds $50 \%$, it can replace part of lime as a flux for sinter. It can not only reduce the production cost but also improve the quality of sinter.

(1) Steel slag is used as a melting agent for blast furnace iron-making. When the slag meets the iron content between $10 \%$ and $30 \%$ and the $\mathrm{CaO}$ content between $40 \%$ and $60 \%$, it can be used as an iron-making solvent. This not only saves the cost but also improves the utilization coefficient

(2) Steel slag is used as a type of raw material for steelmaking and iron-making. When the steel slag meets the mass fraction of iron at about $25 \%$, including $10 \%$ metal iron, it can be directly used for steelmaking and iron-making materials after manual selection and magnetic separation, and the internal direct circulation of steel slag can be realized

The application way of reprocessing of steel slag is

(1) Steel slag is finely grinded and used as a cement admixture [4]. Reasonable slag basicity and free calcium oxide $\mathrm{f}-\mathrm{CaO}$ as well as $\mathrm{C}_{2} \mathrm{~S}$ and $\mathrm{C}_{3} \mathrm{~S}$ and so on. Cement clinker is formed by mixing with water slag in a certain proportion. When the specific surface area of steel slag is $400 \mathrm{~m}^{2} / \mathrm{kg}$, the alkalinity is higher than 1.8, the metal iron content is less than $1 \%$, and the content of $\mathrm{f}-\mathrm{CaO}$ is lower than $5 \%$, it can be used for cement admixture. The application rate of the method is the highest, and the resource utilization of steel slag has been realized 


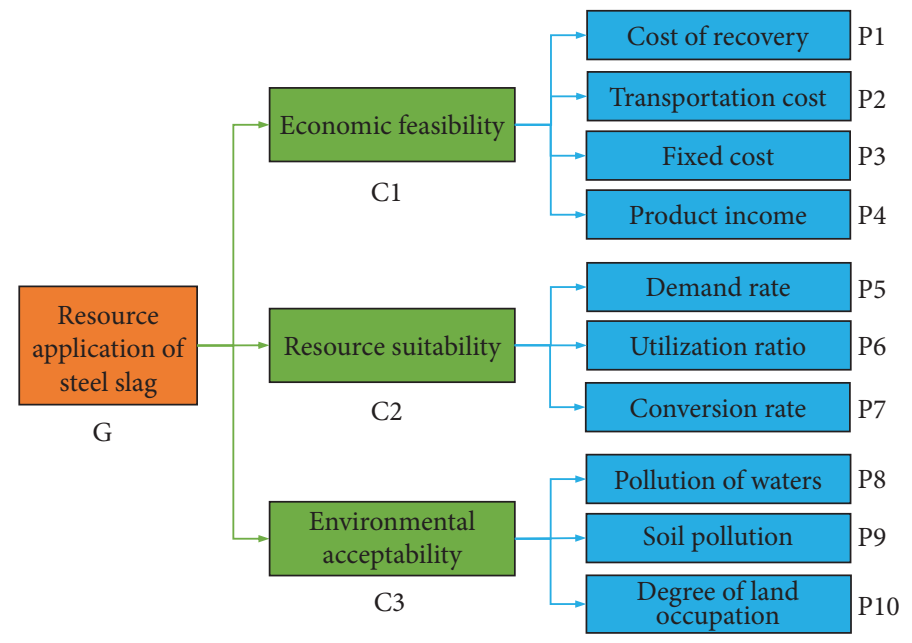

Figure 12: The evaluation index system for resource utilization of steel slag.

(2) Steel slag is used as a base material for pavement. Steel slag has frost resistance and can be applied to a cold climate. When slag satisfies the content of $\mathrm{f}-\mathrm{CaO}$ and $\mathrm{f}-\mathrm{MgO}$ below $4 \%$, it can be used as base material for the road surface. This approach has strong water absorbency and strength in resource utilization

(3) Steel slag is used as agricultural fertilizer. When high phosphorus pig iron is used as raw material for steelmaking, steel slag can be used to make phosphate fertilizer. Its components are $\mathrm{P}_{2} \mathrm{O}_{5}: 15 \% \sim 20 \%, \mathrm{CaO}$ : $40 \% \sim 50 \%, \mathrm{SiO}_{2}: 6 \% \sim 9 \%, \mathrm{MgO}: 3 \% \sim 5 \%$, and $\mathrm{MnO}$ : $2 \% \sim 4 \%$. This method can be used to increase crop drought resistance and disease and pest resistance capacity while increasing production

Based on the approaches about the application of steel slag that are mentioned above, the accumulation and utilization of steel slag can be effectively improved. At the same time, the newly developed technology, such as slag flocculant, steel slag adsorbent, and nanocrystalline ceramic, can be combined with them. A comprehensive evaluation system for resource approaches to the application of steel slag is constructed to provide an intelligent recommendation for steel slag treatment and form an intelligent management system for steel slag resources.

\subsection{Establishment and Evaluation of Evaluation System for} Approaches to Application of Steel Slag. In order to realize the utilization of steel slag resources, it is necessary to take three features of the utilization of steel slag resources into consideration: namely, economic feasibility, resource suitability, and environmental acceptance, so as to change the resource properties of steel slag in a real sense and make it become a favorable resource. The three features can be explained as follows:

Economic feasibility: it refers to the feasibility of steel slag as a resource. The cost-benefit analysis and cost-effectiveness analysis of steel slag resources are mainly made. And the necessity of resource utilization of steel slag is reflected through the estimation and comparison of costs and benefits. Resource suitability: it refers to the possible utilization of steel slag in the process of resource application, according to the actual production and local demand, and the utilization rate of reproduction and the conversion rate of products. The complex chemical composition of steel slag provides the possible utilization of its resources. Environmental acceptability: steel slag treated by systematization can change the present situation of environmental pollution. At present, there are still lots of steel slag for stacking steel slag, which occupy a large number of fertile fields, and also have strong thermal radiation, which greatly affects the surrounding environment.

The diversity of approaches for the application of steel slag resources determines that its evaluation is multiobjective, so its evaluation system should be a multiobjective evaluation system. Complex system engineering is a comprehensive, accurate, objective, and impartial evaluation of the resources approaches for the application of steel slag. It is necessary to establish advanced, optimized, simple, and practical data model and rely on scientific decision-making methods. The quantitative evaluation of the AHP method is not only conducive to making a comprehensive and objective evaluation of the comprehensive utilization rate of steel slag but also reflects the influence of various factors on the comprehensive utilization from different angles, and it is also convenient for guiding and standardizing the management of steel slag [11].

According to the analytic hierarchy process (AHP), the index system is selected and set up at different levels based on its attributes. The evaluation index system is divided into target level (G), criterion level (C), and index level (P). Based on this, a complete hierarchical analytic hierarchy structure model (economy-resources-environment) is established. The hierarchical structure of the model is shown in Figure 12.

From the target level to the index level, the direct impact relationship between various factors is arranged in 3 different levels from top to bottom. Taking the way of resource optimization as the general goal, and taking the economic index, technical index, and environmental index as the evaluation 


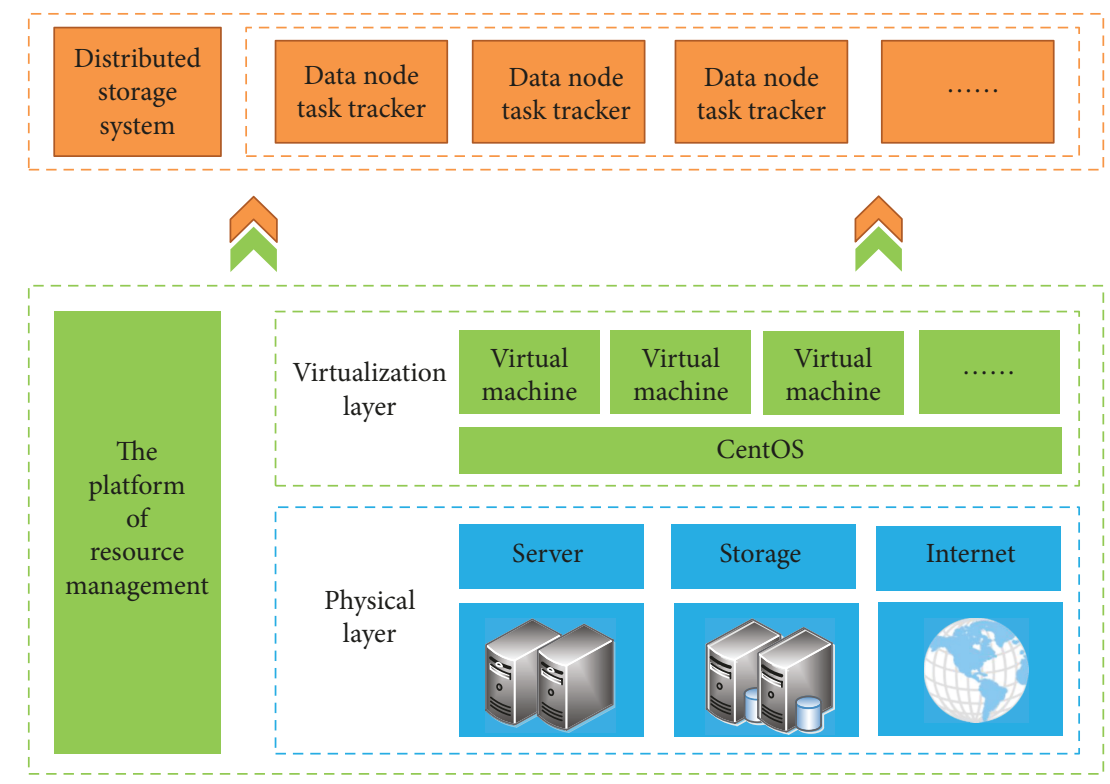

FIGURE 13: Big data platform for iron and steel enterprises bases on Hadoop.

TABLE 2: Satty scoring system of 9 grades.

Scale
$\begin{aligned} & \text { Compared to the two factors, it is equally important } \\ & \text { Compared to the two factors, the former is a little } \\ & \text { more important than the latter } \\ & 5\end{aligned}$
$\begin{array}{r}\text { Compared to the two factors, the former is } \\ \text { significantly more important than the latter } \\ \text { Compared to the two factors, the former is more } \\ \text { important than the latter }\end{array}$
$\begin{array}{r}\text { Compared to the two factors, the former is extremely } \\ \text { important than the latter }\end{array}$
Reciprocal
The intermediate value of the above judgment
The importance of the comparison of the

criterion, the index system of evaluating steel slag resource optimization is constructed, which is divided into 19 indexes.

AHP decomposes the problem with different levels of structure in accordance with the general objectives, goals, criteria, and so on. It is a decision-making scheme based on what was mentioned above, and the basic steps of the AHP algorithm are as follows:

(1) Construction of a model of hierarchical structure

As shown in Figure 13, the G-C-P three-layer structure model is constructed, and $P$ layer is the index layer. It is a specific plan for the safety assessment of the target. It is a total of 10 items. $C$ is a standard layer and a total of 3 items. $G$ is the goal layer, which represents the ultimate goal of evaluation.

(2) Establishment of judgment matrix

Satty scoring system of 9 grades was shown in Table 2. Experts are invited to compare the indexes of the same level with reference to Table 1 and draw the ratio to establish the judgment matrix, as shown in Formula (5):

$$
\begin{aligned}
A & =\left[\begin{array}{cccc}
1 & \frac{w_{1}}{w_{2}} & \ldots & \frac{w_{1}}{w_{n}} \\
\frac{w_{2}}{w_{1}} & \ldots & \ldots & \frac{w_{2}}{w_{n}} \\
\ldots & \ldots & \ldots & \ldots \\
\frac{w_{i}}{w_{1}} & \frac{w_{i}}{w_{1}} & \ldots & 1
\end{array}\right] \\
& =\left[\begin{array}{llll}
a_{11} & a_{12} & \ldots & a_{1 n} \\
a_{21} & a_{22} & \ldots & a_{2 n} \\
\ldots & \ldots & \ldots & \ldots \\
a_{n 1} & a_{12} & \ldots & a_{n n}
\end{array}\right] .
\end{aligned}
$$

(3) Single-sort and consistency check

The characteristic vector $W$ corresponds to the largest eigenvalue $\lambda_{\max }$ of the matrix $A$ is normalized, weight ranking and consistency checking.

(a) Normalization of the matrix $A$ in the form of a column

$$
\overline{a_{i j}}=\frac{a_{i j}}{\sum_{i=1}^{n} a_{i j}}, \quad i, j=1,2, \Lambda, n .
$$

(b) The matrix processed by step (a) is added by line:

$$
w_{i}=\sum_{i=1}^{n} \overline{a_{i j}}, \quad i=1,2, \Lambda, n .
$$


TABLE 3: Reference values for random consistency indexes.

\begin{tabular}{ccccccc}
\hline$n$ & 1 & 2 & 3 & 4 & 5 & 6 \\
\hline RI & 0 & 0 & 0.58 & 0.90 & 1.12 & 1.24 \\
\hline
\end{tabular}

Vector $W=\left[w_{1}, w_{2}, \cdots, w_{n}\right]^{T}$,

$$
w_{i}=\frac{w_{i}}{\sum_{i=1}^{n} w_{i}}
$$

$W=\left[w_{1}, w_{2}, \cdots, w_{n}\right]^{T}$ is the approximate value for the maximum feature vector.

Solving the approximate value of the maximum eigenvalue

$$
\lambda_{\max }=\frac{1}{n}\left(\frac{(A W)_{i}}{W_{i}}\right)
$$

In the formula, $(A W)_{i}$ is the $i$ element of the product vector of the matrix $A$ and $W$. When $\lambda_{\max }<n, A$ is a consistency matrix; when $\lambda_{\max }>n, A$ is a noncongruent matrix. In order to ensure the accuracy of the computation, the consistency of the judgment matrix can be tested by the maximum eigenvalue, using consistency test index CI defined by satty for consistency checking of judgment matrix.

$$
\mathrm{CI}=\frac{\lambda_{\max }-n}{n-1}
$$

where $n$ represents the order of the matrix $A$. The smaller the value of CI is, the better the consistency is.

$$
\mathrm{CR}=\frac{\mathrm{CI}}{\mathrm{RI}}
$$

The ratio of CI to RI is defined as the ratio of random consistency. Reference values for random consistency indexes was shown in Table 3.

The judgment matrix meets the requirements of consistency. When $\mathrm{CR}=\mathrm{CI} / \mathrm{RI}<0.1$, the weight of the calculated weight has high credibility. Otherwise, the judgment matrix is adjusted reasonably and then the above treatment will be done until the consistency check is met.

(4) Total-sort and consistency check

After all layers passed the consistency check, we still have to carry out the consistent test of the overall ranking in order to avoid the inconsistency of the final analysis results. The formula for calculating the total ranking weight of the $i$ element in the $P$ layer
TABle 4: Predicted value of the major chemical composition of steel slag in a steel plant in Hebei (\%).

\begin{tabular}{lccccc}
\hline Composition & $\mathrm{CaO}$ & $\mathrm{Fe}_{2} \mathrm{O}_{3}$ & $\mathrm{SiO}_{2}$ & $\mathrm{Al}_{2} \mathrm{O}_{3}$ & $\mathrm{MgO}$ \\
Content & 33.51 & 17.54 & 15.54 & 7.69 & 5.46 \\
\hline Composition & $\mathrm{f}-\mathrm{CaO}$ & $\mathrm{MnO}$ & $\mathrm{P}_{2} \mathrm{O}_{5}$ & $\mathrm{TiO}_{2}$ & $\mathrm{Na}_{2} \mathrm{O}$ \\
Content & 4.56 & 2.21 & 1.54 & 0.72 & 0.12 \\
\hline
\end{tabular}

to the $G$ level is

$$
P_{i}=\sum_{j=1}^{m} c_{j} p_{i j}, \quad i=1,2, \ldots, n
$$

The ranking weight vectors of elements in the $P$ layer to the $G$ layer can be expressed as

$$
W_{G-P}=\left(p_{1}, p_{2}, \Lambda, p_{n}\right)^{T}
$$

The formula of the conformance test is

$$
\mathrm{CR}=\frac{\sum_{j=1}^{m} p_{j} \mathrm{CI}_{j}}{\sum_{j=1}^{m} p_{j} \mathrm{RI}_{j}}
$$

where CR represents the total consistency ratio of $P$ layer to target $G$ after randomization. When $\mathrm{CR}<0.1$, it meets the requirement of consistency, and the combined weight can be used as the basis for the final decision. In this index system, because of the mutual independence between the evaluation indexes, that is, the contribution of each index to the comprehensive level has no influence. Therefore, the calculation of the comprehensive evaluation can be processed by a linear weighted sum calculation model. When the model to optimize the resource utilization of steel slag, we can get the optimized resource way by calculating the total weight of different resource paths and according to the total weight results.

\section{Case Analysis}

Taking a steel plant in Hebei as an example, with the help of the Hadoop data collection and storage platform built in this paper, the steelmaking process of the steel plant is collected, and the data of steelmaking material and process operation data are screened out. The pretreatment data is used in the trained $\mathrm{CNN}$ network to predict the composition of steel slag and predict the knot. The prediction results are shown in Table 4.

The chemical composition of steel slag produced by a steel plant in Hebei is shown in Table 4. The oxide content of $\mathrm{Ca}, \mathrm{Fe}$, and $\mathrm{Si}$ are the highest, which occupies $66.59 \%$ of the total composition, and the Fe oxide is mainly in the form of $\mathrm{Fe}_{2} \mathrm{O}_{3}$. Based on the classification of resources of steel slag, it can be seen that the resources of steel slag in the steel plant 
TABLE 5: Hierarchical total ranking weight distribution table.

\begin{tabular}{lccccc}
\hline Index & P1 & P2 & P3 & P4 & P5 \\
Weight & 0.13 & 0.11 & 0.10 & 0.12 & 0.11 \\
\hline Index & P6 & P7 & P8 & P9 & P10 \\
Weight & 0.06 & 0.13 & 0.07 & 0.09 & 0.07 \\
\hline
\end{tabular}

TABLE 6: Resource utilization recommendations.

\begin{tabular}{lccc}
\hline Resource approach & $\begin{array}{c}\text { Blast furnace } \\
\text { iron-making agent }\end{array}$ & $\begin{array}{c}\text { Recycled } \\
\text { scrap steel }\end{array}$ & $\begin{array}{c}\text { Cement } \\
\text { admixture }\end{array}$ \\
\hline $\begin{array}{l}\text { Comprehensive } \\
\text { evaluation value }\end{array}$ & 0.48 & 0.57 & 0.76 \\
\hline
\end{tabular}

include: blast furnace iron-making agent, recovery of scrap steel and cement admixture.

With the aid of the AHP-based recommendation system for steel slag resource utilization, the weight of each phase index is obtained based on the established evaluation system. After calculating the weight vector of each pair of paired comparison matrices and passing the consistency test, the results of the evaluation of different aspects of the target layer are synthesized by multiple indexes of the index layer. Based on the steps of the AHP algorithm, the total ranking results are shown in Table 5.

In this index system, each evaluation index has mutual independence, that is, the contribution of each index to the comprehensive level has no influence on each other. Therefore, the calculation of the comprehensive evaluation can be handled by the linear weighted sum calculation model, and the comprehensive evaluation values of the three resource recycling ways of the blast furnace iron-making agent, recycled scrap steel, and cement admixture can be obtained.

According to Table 6, it is known that in the process of exploring the application way of steel slag resource, the three factors of economy, resources, and environment in the evaluation system are considered. The steel slag resource of Hebei steel plant is the cement admixture, which is made into Portland cement with the ratio of water slag. The choice and application of this way will contribute to the development of steel mills and the national economy and the protection of the environment.

\section{Conclusion}

In the paper, a large data storage system of steelmaking history based on the Hadoop platform is constructed while the composition of steel slag, the prediction of steel slag composition is realized with the CNN prediction model, and then the basic information data is provided for the comprehensive evaluation system of the AHP slag resource utilization method. The best way to provide steel slag resource application for steel enterprises is to take three factors, namely, economic feasibility, resource suitability, and environmental acceptance into comprehensive consideration. After making an example analysis, the steel slag recycling application system based on the background of big data constructed in this paper has practical application, which provides an optimization approach for a steel plant in Hebei. Therefore, the system can provide a reference for the sustainable development of the steel enterprises and the recycling of resources. At the same time, the large data of the flow type of steelmaking process can be stored in the platform, so it can make full use of the information of production line and promote the enterprise to enter the information age quickly. It is not only the internal need to improve the environment and achieve sustainable development but also the fundamental of developing the circular economy and building a resource-saving enterprise.

\section{Data Availability}

The data used to support the findings of this study are available from the corresponding author upon request.

\section{Conflicts of Interest}

The authors declare that there are no conflicts of interest regarding the publication of this paper.

\section{Acknowledgments}

This study was financially supported by the Natural Science Foundation of China (no. 51372197), the Key Innovation Team of Shaanxi Province (no. 2014KCT-04), and Xi'an University of Science and Technology Doctoral start-up project (no. 2018QDJ011).

\section{References}

[1] V. Ducman and A. Mladenovič, "The potential use of steel slag in refractory concrete," Materials Characterization, vol. 62, no. 7, pp. 716-723, 2011.

[2] K. Matern, T. Rennert, and T. Mansfeldt, "Molybdate adsorption from steel slag eluates by subsoils," Chemosphere, vol. 93, no. 9, pp. 2108-2115, 2013.

[3] S. Moon, J. Lee, X. Sun, and Y. S. Kee, "Optimizing the Hadoop MapReduce framework with high-performance storage devices," Journal of Supercomputing, vol. 71, no. 9, pp. 3525-3548, 2015.

[4] J. Kawahara, C. J. Brown, S. P. Miller et al., "BrainNetCNN: convolutional neural networks for brain networks; towards predicting neurodevelopment," NeuroImage, vol. 146, pp. 10381049, 2017.

[5] A. Rabkin and R. H. Katz, "How Hadoop clusters break," IEEE Software, vol. 30, no. 4, pp. 88-94, 2013.

[6] D. Gerardi, T. E. Marlin, and C. L. E. Swartz, "Optimization of primary steelmaking purchasing and operation under raw material uncertainty," Industrial \& Engineering Chemistry Research, vol. 52, no. 35, pp. 12383-12398, 2013.

[7] Z. Yao and C. Lv, "GCr15 bearing steel converter steelmaking process research," Steel Research, vol. 37, pp. 45-47, 2009.

[8] M. Matsugu, K. Mori, Y. Mitari, and Y. Kaneda, "Subject independent facial expression recognition with robust face detection using a convolutional neural network," Neural Networks, vol. 16, no. 5-6, pp. 555-559, 2003.

[9] M. Karami, R. Safabakhsh, and M. Rahmati, "Modular cellular neural network structure for wave-computing-based image processing," ETRI Journal, vol. 35, no. 2, pp. 207-217, 2013. 
[10] W. Wang, S. Neogi, D. Y. F. Lai, C. Zeng, C. Wang, and D. Zeng, "Effects of industrial and agricultural waste amendment on soil greenhouse gas production in a paddy field in southeastern China," Atmospheric Environment, vol. 164, pp. 239-249, 2017.

[11] W. Pedrycz and M. Song, "Analytic hierarchy process (AHP) in group decision making and its optimization with an allocation of information granularity," IEEE Transactions on Fuzzy Systems, vol. 19, no. 3, pp. 527-539, 2011. 


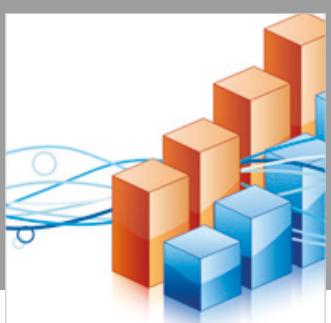

Advances in

Operations Research

\section{-n-m}
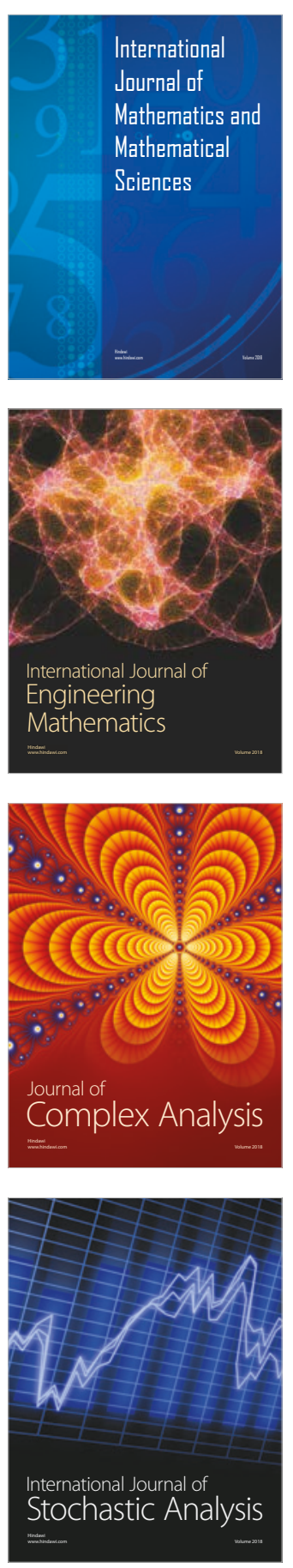
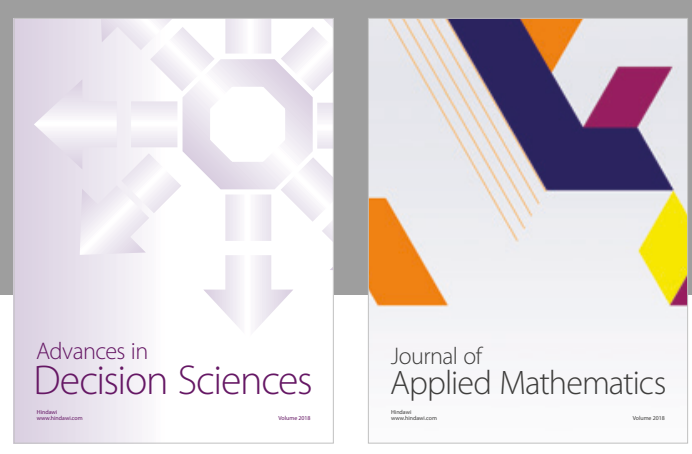

Journal of

Applied Mathematics
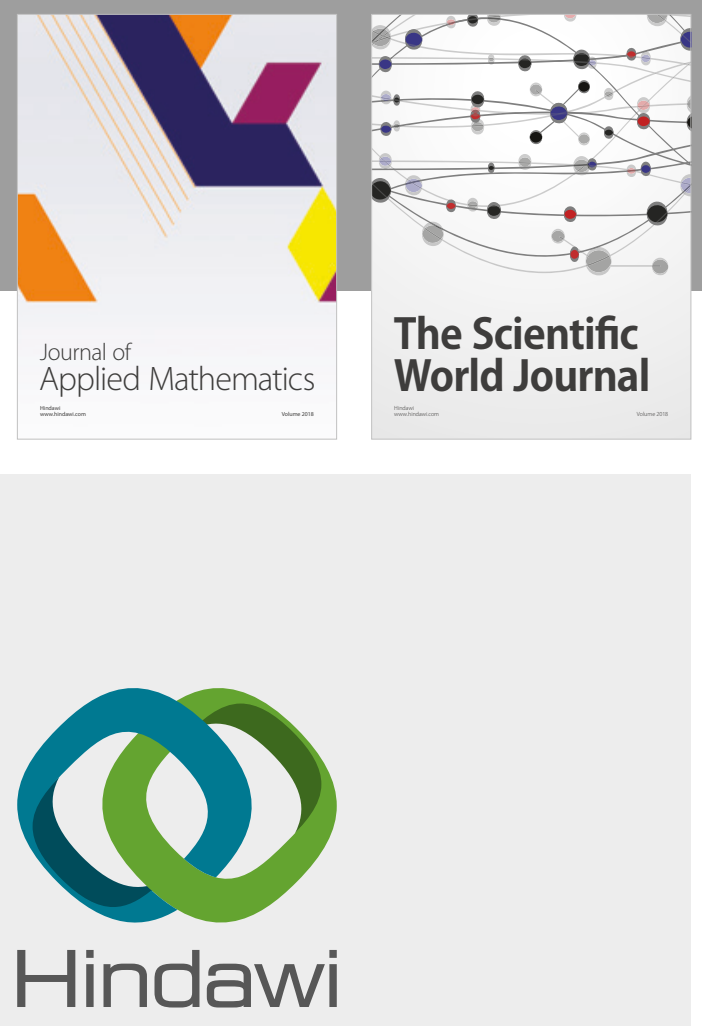

Submit your manuscripts at

www.hindawi.com

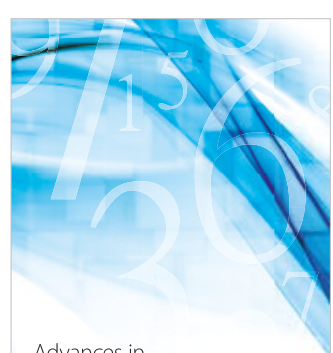

Advances in
Numerical Analysis
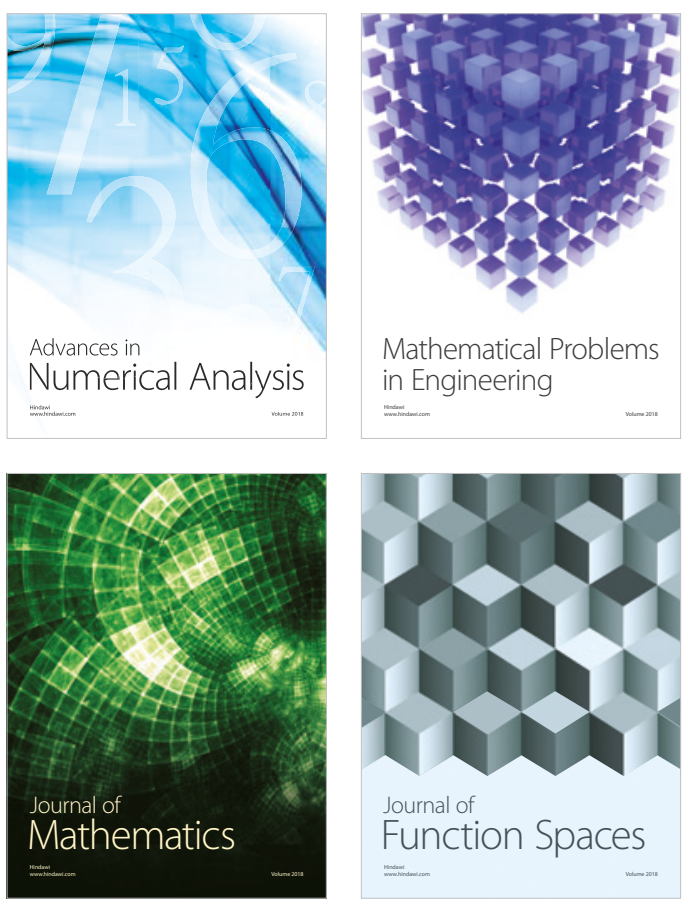

Mathematical Problems in Engineering

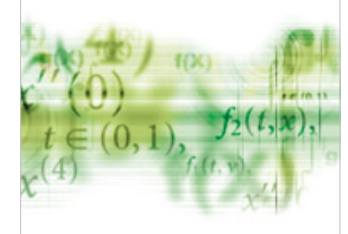

International Journal of

Differential Equations

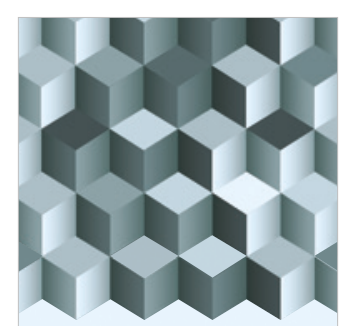

Journal of

Function Spaces
The Scientific

World Journal

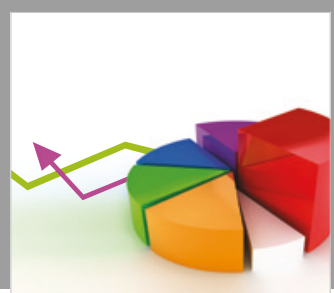

Journal of

Probability and Statistics
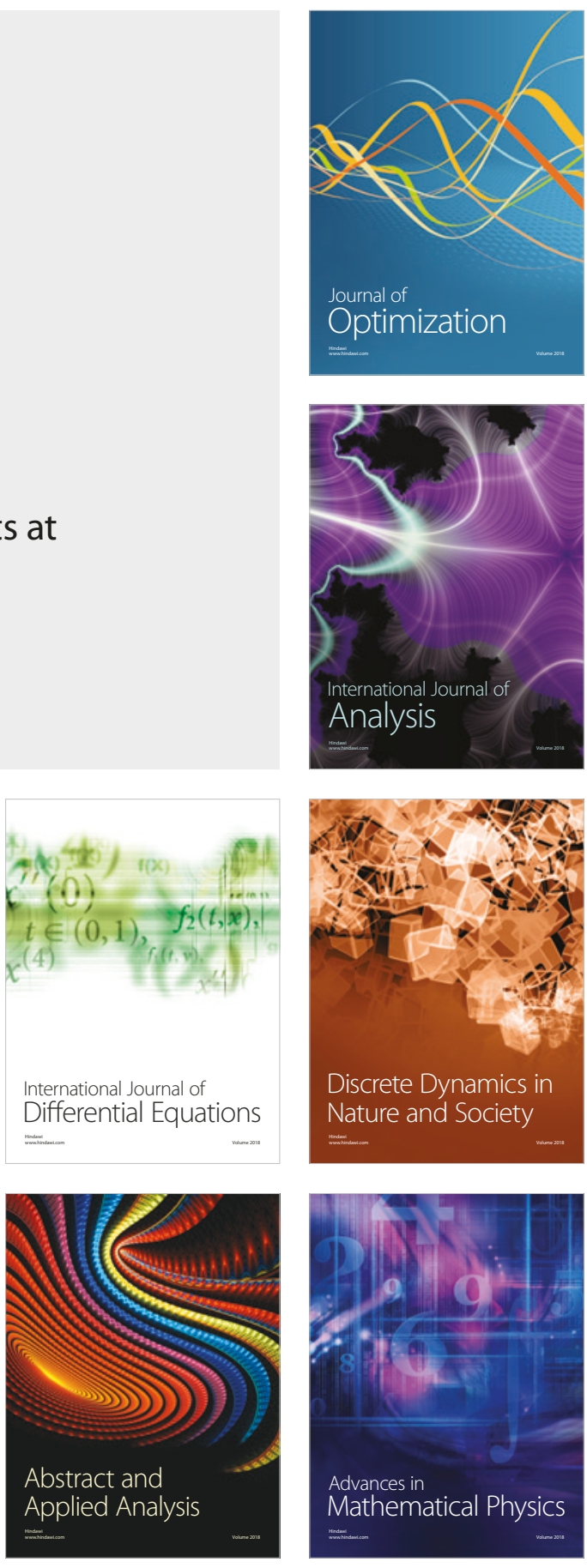